\title{
Prognostic Significance of Cystatin C in Patients With ST-Elevation Myocardial Infarction
}

\author{
Eiji Ichimoto, MD; Kigen Jo, MD*; Yoshio Kobayashi, MD; \\ Toshihisa Inoue, MD*; Yoshitake Nakamura, MD*; Nakabumi Kuroda, MD; \\ Akira Miyazaki, MD*; Issei Komuro, MD
}

\begin{abstract}
Background: Cystatin C is reportedly a better endogenous marker of glomerular filtration rate than serum creatinine, so the prognostic value of cystatin C in patients with ST-elevation myocardial infarction (MI) was evaluated in the present study.

Methods and Results: A total of 71 patients who underwent percutaneous coronary intervention for ST-segment elevation $\mathrm{MI}<24 \mathrm{~h}$ from symptom onset were included. According to cystatin $\mathrm{C}$ level, patients were classified into 2 groups: (1) higher cystatin $C$ group ( $n=33)$ and (2) lower cystatin $C$ group $(n=38)$. There was a trend toward more in-hospital deaths in patients with the higher cystatin $\mathrm{C}$ level compared with the lower cystatin $\mathrm{C}$ level group (15.2\% vs $2.6 \%, \mathrm{P}=0.06$ ). Mean duration of clinical follow-up was 5.6 \pm 2.8 months. There was no significant difference in death, reinfarction, disabling stroke or target lesion revascularization between the 2 groups. However, a higher incidence of rehospitalization for congestive heart failure was observed in patients with the higher cystatin $\mathrm{C}$ level than in those with the lower cystatin $\mathrm{C}$ level $(15.2 \%$ vs $0 \%, \mathrm{P}=0.01)$.

Conclusions: Cystatin C may be associated with more cardiovascular events, mainly rehospitalization for congestive heart failure, after percutaneous coronary intervention in patients with ST-elevation MI. (Circ J 2009; 73: $1669-1673$ )
\end{abstract}

Key Words: Acute myocardial infarction; Creatinine; Cystatin C; Renal failure

$\mathbf{R}$ ecently, much attention has been paid to the relationship between chronic kidney disease and cardiovascular events. ${ }^{1-8}$ Renal function is estimated by serum creatinine concentration or estimation of creatinine clearance by the Cockcroft-Gault and Modification of Diet in Renal Disease (MDRD) equations. ${ }^{7,8}$ However, creatinine concentration is an unreliable estimate of the glomerular filtration rate (GFR), ${ }^{1,2}$ because it is influenced by factors such as age, gender, muscle mass, physical activity, and diet. ${ }^{9}$ Because of the nonlinear relationship between creatinine concentration and GFR, it is insensitive to small decreases in GFR or mild renal dysfunction. ${ }^{10}$ Cystatin $\mathrm{C}$ is a cysteine protease inhibitor involved in the catabolism of proteins. It is produced in all nucleated cells at a constant rate and is freely filtered by the glomerulus without secretion or subsequent reabsorption to the blood flow. ${ }^{11}$ Because it has been shown that cystatin $\mathrm{C}$ is a better endogenous marker of GFR than serum creatinine, ${ }^{11,12}$ the prognostic value of cystatin $\mathrm{C}$ in patients with ST-elevation myocardial infarction (MI) was evaluated in the present study.

\section{Editorial p 1593}

\section{Methods}

\section{Patients}

Between December 2006 and July 2007, 72 consecutive patients underwent percutaneous coronary intervention (PCI) for ST-segment elevation $\mathrm{MI}<24 \mathrm{~h}$ from symptom onset at Chiba Cardiovascular Center. ST-segment elevation MI was diagnosed by (1) typical chest pain lasting $>30$ min, (2) ST-segment elevation in at least 2 contiguous leads or left bundle-branch block, and (3) typical increase and decrease of serum creatine kinase concentration above twice the upper limit of normal. Exclusion criterion was age 90 years and over $(n=1)$. Thus 71 patients were included in the present study. PCI was performed using standard techniques after written informed consent was given. Before discharge (13.5 \pm 3.5 days after admission), coronary angiography and left ventriculography were repeated. This study was approved by the local council on human research.

\section{Laboratory Analysis}

Before PCI, blood samples were collected and serum cystatin $\mathrm{C}$ measurement was performed by colloidal gold particle-enhanced colorimetric immunoassay (Nescauto GC

(Received October 15, 2008; revised manuscript received March 26, 2009; accepted April 20, 2009; released online July 13, 2009)

Department of Cardiovascular Science and Medicine, Chiba University Graduate School of Medicine, Chiba, *Chiba Cardiovascular Center, Ichihara, Japan

No grant.

Mailing address: Eiji Ichimoto, MD, Department of Cardiovascular Science and Medicine, Chiba University Graduate School of Medicine, 1-8-1 Inohana, Chuo-ku, Chiba 260-8670, Japan. E-mail: e.ichimoto@ nifty.com

All rights are reserved to the Japanese Circulation Society. For permissions, please e-mail: cj@j-circ.or.jp 
Table 1. Baseline Characteristics

\begin{tabular}{|c|c|c|c|}
\hline & Higher cystatin $C(n=33)$ & Lower cystatin $(-)(n=38)$ & $P$ value \\
\hline Age (years) & $66.5 \pm 12.6$ & $61.9 \pm 10.4$ & 0.09 \\
\hline Male, $\mathrm{n}(\%)$ & $27(81.8)$ & $35(92.1)$ & 0.19 \\
\hline Hypertension, n (\%) & $16(48.5)$ & $23(60.5)$ & 0.31 \\
\hline Hypercholesterolemia, n (\%) & $21(63.6)$ & $25(65.8)$ & 0.85 \\
\hline Diabetes mellitus, n (\%) & $14(42.4)$ & $19(50.0)$ & 0.52 \\
\hline Current smokers, $\mathrm{n}(\%)$ & $23(69.7)$ & $22(57.9)$ & 0.30 \\
\hline Prior myocardial infarction, $\mathrm{n}(\%)$ & $6(18.2)$ & $7(18.4)$ & 0.98 \\
\hline Prior PCI, n $(\%)$ & $3(9.1)$ & $1(2.6)$ & 0.24 \\
\hline Prior bypass surgery, $\mathrm{n}(\%)$ & $0(0.0)$ & $1(2.6)$ & 0.35 \\
\hline Creatinine, $\mathrm{mg} / \mathrm{dl}$ & $0.93 \pm 0.22$ & $0.72 \pm 0.14$ & $<0.01$ \\
\hline Left ventricular ejection fraction $(\%)^{*}$ & $49.4 \pm 11.7$ & $53.3 \pm 9.3$ & 0.18 \\
\hline Killip class, $\mathrm{n}(\%)$ & & & 0.13 \\
\hline 1 & $25(75.8)$ & $35(92.1)$ & \\
\hline 2 & $2(6.1)$ & $2(5.3)$ & \\
\hline 3 & $2(6.1)$ & $1(2.6)$ & \\
\hline 4 & $4(12.1)$ & $0(0.0)$ & \\
\hline Time from onset of symptoms to hospital presentation (h) & $4.8 \pm 2.9$ & $5.3 \pm 3.4$ & 0.51 \\
\hline Time from hospital presentation to angioplasty (h) & $1.4 \pm 0.7$ & $1.2 \pm 0.6$ & 0.15 \\
\hline Peak creatine kinase, IU/L & $3,706 \pm 2,382$ & $2,878 \pm 2,406$ & 0.15 \\
\hline \multicolumn{4}{|l|}{ Medication at discharge } \\
\hline Aspirin, n (\%) & $33(100.0)$ & $38(100.0)$ & NA \\
\hline Ticlopidine, n (\%) & $31(93.9)$ & 37 (97.4) & 0.47 \\
\hline ACE inhibitors/ARB, n (\%) & $20(60.6)$ & $25(65.8)$ & 0.65 \\
\hline$\beta$-blockers, $\mathrm{n}(\%)$ & $6(18.2)$ & $9(23.7)$ & 0.57 \\
\hline Statins, n (\%) & $17(51.5)$ & $21(55.3)$ & 0.75 \\
\hline
\end{tabular}

*Evaluated by transthoracic echocardiography.

PCI, percutaneous coronary intervention; NA, not applicable; ACE, angiotensin-converting enzyme; ARB, angiotensin receptor blocker.

Table 2. Angiographic and Procedural Characteristics

\begin{tabular}{|c|c|c|c|}
\hline & Higher cystatin $C(n=33)$ & Lower cystatin C (n=38) & $P$ value \\
\hline Infarct-related vessel & & & 0.45 \\
\hline Left anterior descending, $\mathrm{n}(\%)$ & $15(45.5)$ & $23(60.5)$ & \\
\hline Left circumflex, $\mathrm{n}(\%)$ & $5(15.2)$ & $4(10.5)$ & \\
\hline Right coronary artery, n (\%) & $13(39.4)$ & $11(28.9)$ & \\
\hline Left main, $\mathrm{n}(\%)$ & $0(0.0)$ & $0(0.0)$ & \\
\hline Saphenous vein graft, n (\%) & $0(0.0)$ & $0(0.0)$ & \\
\hline No. of diseased vessels, $\mathrm{n}(\%)$ & & & 0.91 \\
\hline 1 & $18(54.5)$ & $19(50.0)$ & \\
\hline 2 & $9(27.3)$ & $12(31.6)$ & \\
\hline 3 & $6(18.2)$ & $7(18.4)$ & \\
\hline Thrombectomy, n (\%) & $32(97.0)$ & $32(84.2)$ & 0.07 \\
\hline Stent implanted, n (\%) & $33(100.0)$ & $37(97.4)$ & 0.35 \\
\hline Stents/lesion & $1.15 \pm 0.36$ & $1.24 \pm 0.44$ & 0.35 \\
\hline Stent diameter, $\mathrm{mm}$ & $3.29 \pm 0.38$ & $3.27 \pm 0.45$ & 0.80 \\
\hline Stent length, mm & $22.4 \pm 9.0$ & $23.2 \pm 10.4$ & 0.71 \\
\hline Maximum balloon diameter, $\mathrm{mm}$ & $3.31 \pm 0.36$ & $3.27 \pm 0.45$ & 0.68 \\
\hline Maximum balloon inflation, atm & $13.8 \pm 1.7$ & $13.8 \pm 1.5$ & 0.83 \\
\hline \multicolumn{4}{|l|}{ TIMI flow, n (\%) } \\
\hline Before procedure & & & 0.67 \\
\hline 0 & $27(81.8)$ & $30(78.9)$ & \\
\hline 1 & $5(15.2)$ & $5(13.2)$ & \\
\hline 2 & $1(3.0)$ & $3(7.9)$ & \\
\hline 3 & $0(0.0)$ & $0(0.0)$ & \\
\hline After procedure & & & 0.94 \\
\hline 0 & $0(0.0)$ & $0(0.0)$ & \\
\hline 1 & $0(0.0)$ & $0(0.0)$ & \\
\hline 2 & $5(15.2)$ & $6(15.8)$ & \\
\hline 3 & $28(84.8)$ & $32(84.2)$ & \\
\hline
\end{tabular}

TIMI, Thrombosis In Myocardial Infarction.

Cystatin C, Alfresa Pharma, Osaka, Japan) with a Hitachi 7600-110 automatic analyzer. Serum creatinine concentration was determined by enzymatic assay (Aquaauto Kainos CRE-II, Kainos, Tokyo, Japan). The upper reference level was $1.04 \mathrm{mg} / \mathrm{dl}$. Estimated GFR (eGFR) was calculated according to the MDRD equation modified for Japanese patients. ${ }^{13}$

Follow-up

All patients received aspirin $100 \mathrm{mg}$ daily indefinitely. 
Ticlopidine $100 \mathrm{mg}$ twice daily was given for at least 1 month to patients undergoing stenting. Baseline demographic and clinical data along with in-hospital outcomes were obtained by review of the medical records and procedural reports. Clinical follow-up data were obtained from outpatient record reviews or telephone interviews. General practitioners, referring cardiologists, and patients were contacted as necessary for additional information. Reinfarction was defined by the presence of recurrent ischemic symptoms or electrocardiographic changes accompanied by a creatine kinase concentration that was more than twice the upper limit of the normal range or more than $50 \%$ higher than the previous value obtained during hospitalization. Disabling stroke was defined as an acute neurologic deficit that lasted more than $24 \mathrm{~h}$ and affected the ability to perform daily activities or resulted in death. Heart failure requiring hospitalization was diagnosed by clinical signs and symptoms, and chest radiographic findings. Stent thrombosis was defined as the presence of an acute coronary syndrome with angiographic or autopsy evidence of thrombus or occlusion. Angiographic follow-up was performed at 3 or 6 months or earlier if noninvasive evaluation or clinical presentation suggested ischemia. The occurrence of major clinical events was recorded and included death from any cause, reinfarction, target lesion revascularization (TLR), disabling stroke, or rehospitalization for congestive heart failure $(\mathrm{CHF})$.

\section{Statistical Analysis}

Statistical analysis was performed with StatView 5.0 software (SAS Institute, Cary, NC, USA) except receiveroperating characteristic (ROC) curve analysis, which was performed with SPSS 11.0 (SPSS Inc, Chicago, IL, USA). Continuous variables are expressed as mean \pm SD and categorical variables as frequency (\%). Continuous variables were compared using Student's t-test. Categorical variables were compared with chi-square statistics. A ROC curve analysis was used to determine optimal cutoff point of cystatin $\mathrm{C}$ level to predict cardiovascular events during followup. It was calculated by determining the cystatin $\mathrm{C}$ level that provided the greatest sum of sensitivity and specificity. The Kaplan-Meier method was used for the estimation of event-free survival during follow-up and differences between the curves were compared using log-rank analysis. $P$ value $<0.05$ was considered significant. Univariate analysis of factors affecting event-free survival was performed using factors in Tables $\mathbf{1}$ and $\mathbf{2}$. Multivariate analysis was

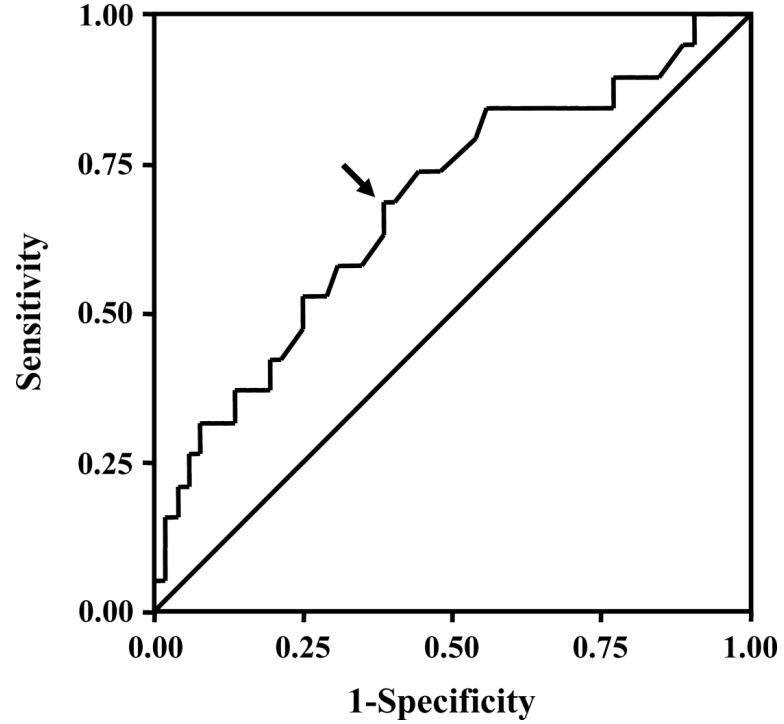

Figure 1. Receiver-operating characteristic curve for cystatin $\mathrm{C}$ (area under the curve $0.68,95 \% \mathrm{CI} 0.54-0.82, \mathrm{P}<0.05)$. Arrow indicates the cutoff point (0.955).

performed by the Cox proportional-hazards model. Variables with $\mathrm{P}<0.1$ in the univariate analysis were included in the multivariate model.

\section{Results}

ROC curve analysis demonstrated cystatin $\mathrm{C} 0.955$ as the cutoff level to predict cardiovascular events during followup (Figure 1). Patients were classified into 2 groups: (1) the higher cystatin $C$ group $(\geq 0.96 \mathrm{mg} / \mathrm{L})(\mathrm{n}=33)$ and $(2)$ the lower cystatin $\mathrm{C}$ group $(<0.96 \mathrm{mg} / \mathrm{L})(\mathrm{n}=38)$. Baseline clinical characteristics are presented in Table 1. Serum creatinine concentration was higher in the higher cystatin $\mathrm{C}$ group than in the lower cystatin $\mathrm{C}$ group. There was no significant difference in Killip class, peak creatine kinase concentration or medication at discharge between the 2 groups. Table 2 shows angiographic and procedural characteristics. Thrombosis In Myocardial Infarction grade 2 or 3 flow was achieved in all patients and none received drugeluting stents. There was a trend toward more in-hospital deaths in patients with the higher cystatin $\mathrm{C}$ concentration

Table 3. In-Hospital and Out-of-Hospital Outcomes

\begin{tabular}{lccc}
\hline & Higher cystatin C $(\mathrm{n}=33)$ & Lower cystatin C $(\mathrm{n}=38)$ & P value \\
\hline In-hospital & & & \\
Cardiac death, $\mathrm{n}(\%)$ & $5(15.2)$ & $1(2.6)$ & 0.06 \\
Noncardiac death, $\mathrm{n}(\%)$ & $0(0.0)$ & $1(2.6)$ & 0.88 \\
Reinfarction, $\mathrm{n}(\%)$ & $1(3.0)$ & $0(0.0)$ & 0.28 \\
Revascularization, $\mathrm{n}(\%)$ & $1(3.0)$ & $0(0.0)$ & 0.28 \\
Disabling stroke, $\mathrm{n}(\%)$ & $0(0.0)$ & $0(0.0)$ & NA \\
Out-of-hospital & $0(0.0)$ & $0(0.0)$ & NA \\
Cardiac death, $\mathrm{n}(\%)$ & $0(0.0)$ & $0(0.0)$ & NA \\
Noncardiac death, $\mathrm{n}(\%)$ & $0(0.0)$ & $0(0.0)$ & NA \\
Reinfarction, $\mathrm{n}(\%)$ & $2(6.1)$ & $4(10.5)$ & 0.46 \\
Revascularization, $\mathrm{n}(\%)$ & $0(0.0)$ & $0(0.0)$ & NA \\
Disabling stroke, $\mathrm{n}(\%)$ & $5(15.2)$ & $0(0.0)$ & 0.01 \\
Re-hospitalization for CHF, $\mathrm{n}(\%)$ & $0(0.0)$ & $0(0.0)$ & NA \\
Stent thrombosis, $\mathrm{n}(\%)$ & &
\end{tabular}

CHF, congestive heart failure. Other abbreviation see in Table 1. 
Table 4. Multivariate Analysis

\begin{tabular}{lccc}
\hline & HR & CI & P value \\
\hline Killip class $\geq 2$ & 2.77 & $1.40-11.0$ & 0.02 \\
Time from hospital presentation to angioplasty $(\mathrm{h})$ & 1.79 & $1.08-4.15$ & 0.03 \\
Cystatin C $(\geq 0.96 \mathrm{mg} / \mathrm{L})$ & 2.17 & $1.07-6.98$ & 0.04 \\
Prior myocardial infarction & 1.18 & $0.39-3.60$ & 0.18 \\
Creatinine elevation & 1.16 & $0.33-4.06$ & 0.18 \\
Age (years) & 1.04 & $0.99-1.09$ & 0.37 \\
\hline
\end{tabular}

HR, hazard ratio; CI, confidence interval.
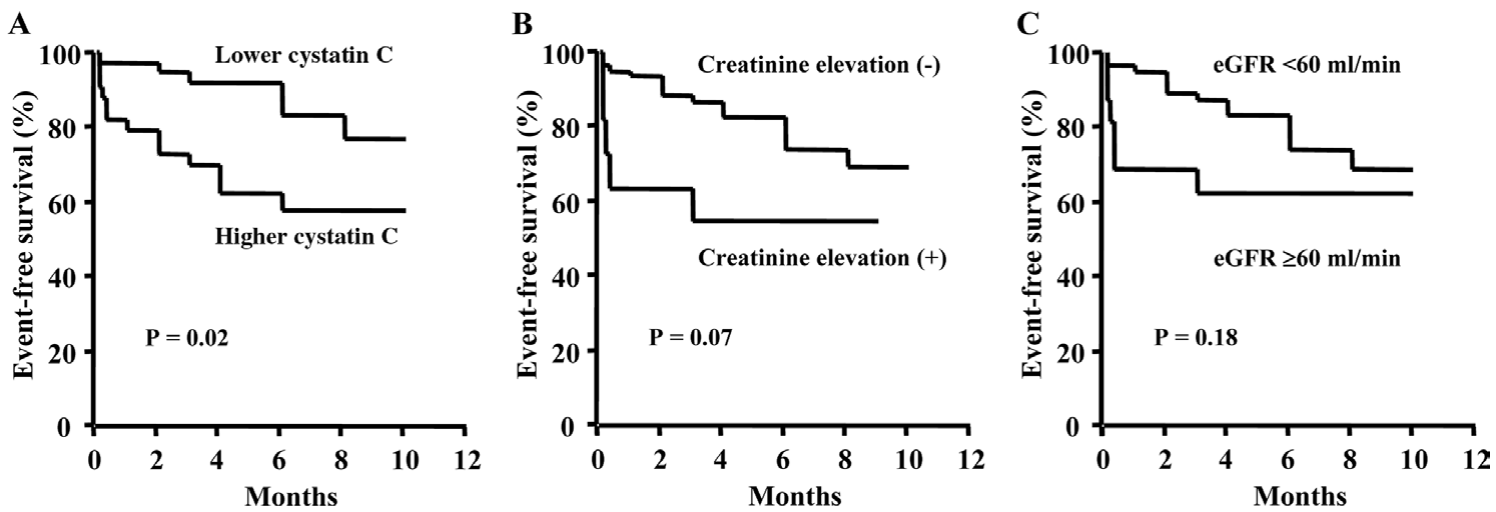

Figure 2. Event-free survival curves according to cystatin $\mathbf{C}(\mathbf{A})$, serum creatinine concentration (B), and estimated glomerular filtration rate (eGFR) $(\mathbf{C})$.

compared with the lower cystatin C group (Table 3). Before discharge (13.5 \pm 3.5 days after admission), left ventriculography was performed in 14 and 23 patients with the higher and lower cystatin $\mathrm{C}$ concentrations, respectively. Left ventricular ejection fraction was not different between the 2 groups $(51.0 \pm 10.2 \%$ vs $52.9 \pm 9.6 \%, \mathrm{P}=0.58)$.

Mean duration of clinical follow-up was 5.6 \pm 2.8 months. There was no significant difference in death, reinfarction, TLR, and disabling stroke between the 2 groups (Table 3 ). However, rehospitalization for CHF was higher in the higher cystatin $\mathrm{C}$ group than in the lower cystatin $\mathrm{C}$ group. Kaplan-Meier curves show lower event-free survival in patients with the higher cystatin $\mathrm{C}$ concentration than in those with the lower cystatin C concentration (Figure 2A). On the other hand, there was no statistical difference in event-free survival between patients with and without serum creatinine elevation (Figure 2B). There was no statistical difference in event-free survival between patients with eGFR $<60 \mathrm{ml} / \mathrm{min}$ and those with eGFR $\geq 60 \mathrm{ml} / \mathrm{min}$ (Figure 2C). Table 4 presents the results of multivariate analysis. Cystatin $\mathrm{C}$ was an independent predictor of cardiovascular events during follow-up.

\section{Discussion}

The present study showed more cardiovascular events in patients with the higher cystatin $\mathrm{C}$ concentration who underwent PCI for ST-elevation MI. On the other hand, there was no statistical difference in cardiovascular events between patients with and without an elevated serum creatinine concentration.

Cardiac diseases are responsible for almost 50\% of allcause mortality in patients with end-stage renal disease. ${ }^{14} \mathrm{It}$ was recently reported that even mild renal dysfunction is associated with cardiovascular events. ${ }^{1-8}$ Go et al. ${ }^{4}$ evalu- ated the relationship between the eGFR and cardiovascular events in 1,120,295 adults. During follow-up (median 2.84 years), the adjusted hazard ratio for death was 1.2 with an eGFR of $45-59 \mathrm{ml} \cdot \mathrm{min}^{-1} \cdot 1.73 \mathrm{~m}^{-2}, 1.8$ with an eGFR of $30-44 \mathrm{ml} \cdot \mathrm{min}^{-1} \cdot 1.73 \mathrm{~m}^{-2}, 3.2$ with an eGFR of $15-29 \mathrm{ml}$. $\mathrm{min}^{-1} \cdot 1.73 \mathrm{~m}^{-2}$, and 5.9 with an eGFR of $<15 \mathrm{ml} \cdot \mathrm{min}^{-1}$. $1.73 \mathrm{~m}^{-2}$, and the adjusted hazard ratio for cardiovascular events increased inversely with the eGFR: 1.4, 2.0, 2.8, and 3.4 , respectively. Recently Shiba et $\mathrm{al}^{5}$ reported the prognostic importance of chronic kidney disease in Japanese patients with chronic heart failure. Their Kaplan-Meier analysis revealed that the incidence of the combined events of all-cause death and admission for CHF was significantly higher in patients with reduced GFR.

The Framingham Heart Study showed that $8.9 \%$ of men and $8.0 \%$ of women had renal dysfunction defined as serum creatinine $>1.5 \mathrm{mg} / \mathrm{dl}$ and $>1.4 \mathrm{mg} / \mathrm{dl}$, respectively. ${ }^{8}$ Serum creatinine concentration or an estimation of creatinine clearance using the Cockcroft-Gault and MDRD equations has been the standard for estimating renal function.7,8 However, creatinine concentration is influenced by factors such as age, gender, muscle mass, physical activity, and diet. ${ }^{9}$ so it is insensitive to small decreases in GFR or mild renal dysfunction. ${ }^{10}$ Cystatin $\mathrm{C}$ has been introduced as a better endogenous marker of GFR. ${ }^{11,12}$ Jernberg et al ${ }^{1}$ demonstrated cystatin $\mathrm{C}$ as a predictor of outcome in patients with non-ST-elevation acute coronary syndrome. The risk of death during follow-up increased with increasing levels of cystatin C. Patients in the $2^{\text {nd }}, 3^{\text {rd }}$, and $4^{\text {th }}$ quartiles of cystatin $\mathrm{C}$ had a relative risk of subsequent death of 1.8 , 3.2, and 11.7 compared with the lowest quartile. There was a significant association between cystatin $\mathrm{C}$ concentration and risk of subsequent MI. In their Cox regression model, cystatin $\mathrm{C}$ concentration was an independent predictor of mortality, although it was not for subsequent MI. In the 
present study, there was no difference in cardiac death during follow-up between patients with the lower and higher cystatin $\mathrm{C}$ concentration, which may be explained by the smaller number of patients and relatively short follow-up.

Previous studies 2,3 showed a higher incidence of heart failure in patients with renal dysfunction. Sarnak et $\mathrm{al}^{2}$ evaluated an incidence of heart failure in 4,384 persons without previous heart failure who had measurements of cystatin $\mathrm{C}$ and serum creatinine. During a median followup of 8.3 years, $763(17 \%)$ participants developed heart failure. In Cox proportional hazards models, sequential quintiles of cystatin $\mathrm{C}$ concentration were associated with a stepwise increased risk for heart failure but quintiles of serum creatinine concentration were not. Early in the pathogenesis of heart failure, increased left atrial filling pressures trigger the release of atrial natriuretic peptide and inhibition of vasopressin, which leads to decreased renal sympathetic tone and diuresis. ${ }^{15}$ Even mild renal dysfunction blunts these compensatory mechanisms ${ }^{16}$ and may lead to sodium and water retention and extracellular fluid volume expansion, which can accelerate the progression of clinical heart failure. ${ }^{15,17}$ Renal dysfunction is also associated with diastolic dysfunction, left ventricular hypertrophy and vascular stiffness. ${ }^{3}$ Furthermore, renal dysfunction may indicate a generalized atherosclerosis and vascular damage. ${ }^{18}$ Cystatin C concentration may be useful to stratify high-risk patients with ST-elevation MI. Strategies to prevent heart failure, such as angiotensin-converting enzyme inhibitors and angiotensin II receptor blockers, may be more important in patients with an elevated cystatin $\mathrm{C}$ concentration. ${ }^{19}$

\section{Study Limitations}

In the present study, a higher incidence of rehospitalization for $\mathrm{CHF}$ occurred in patients with the higher cystatin $\mathrm{C}$ concentration than in those with the lower cystatin $\mathrm{C}$ concentration. However, there was no significant difference in death, reinfarction, disabling stroke, or TLR between the 2 groups. However, this was a retrospective study with a small number of patients and relatively short follow-up, which might be associated with the observed lack of a significant difference between groups. Further studies with a larger number of patients and longer follow-up are required to evaluate the usefulness of cystatin $\mathrm{C}$ concentration for predicting death, reinfarction, disabling stroke, or TLR during follow-up after MI.

\section{Conclusion}

Cystatin C may be associated with more cardiovascular events, mainly because of rehospitalization for $\mathrm{CHF}$, after PCI in patients with ST-elevation MI.

\section{References}

1. Jernberg T, Lindahl B, James S, Larsson A, Hansson LO, Wallentin L. Cystatin C: A novel predictor of outcome in suspected or confirmed non-ST-elevation acute coronary syndrome. Circulation 2004; 110: $2342-2348$.

2. Sarnak MJ, Katz R, Stehman-Breen CO, Fried LF, Jenny NS, Psaty $\mathrm{BM}$, et al. Cystatin $\mathrm{C}$ concentration as a risk factor for heart failure in older adults. Ann Intern Med 2005; 142: 497-505.

3. Moran A, Katz R, Smith NL, Fried LF, Sarnak MJ, Seliger SL, et al. Cystatin $\mathrm{C}$ concentration as a predictor of systolic and diastolic heart failure. J Card Fail 2008; 14: 19-26.

4. Go AS, Chertow GM, Fan D, McCulloch CE, Hsu CY. Chronic kidney disease and the risks of death, cardiovascular events, and hospitalization. N Engl J Med 2004; 351: 1296-1305.

5. Shiba N, Matsuki M, Takahashi J, Tada T, Watanabe J, Shimokawa $\mathrm{H}$. Prognostic importance of chronic kidney disease in Japanese patients with chronic heart failure. Circ J 2008; 72: 173-178.

6. Ishio N, Kobayashi Y, Takebayashi H, Iijima Y, Kanda J, Nakayama $\mathrm{T}$, et al. Impact of drug-eluting stents on clinical and angiographic outcomes in dialysis patients. Circ J 2007; 71: 1525-1529.

7. Edwards NC, Steeds RP, Ferro CJ, Townend JN. The treatment of coronary artery disease in patients with chronic kidney disease. $Q J$ Med 2006; 99: 723-736.

8. Culleton BF, Larson MG, Evans JC, Wilson PW, Barrett BJ, Parfrey PS, et al. Prevalence and correlates of elevated serum creatinine levels: The Framingham Heart Study. Arch Intern Med 1999; 159: $1785-1790$.

9. Hsu CY, Chertow GM, Curhan GC. Methodological issues in studying the epidemiology of mild to moderate chronic renal insufficiency. Kidney Int 2002; 61: 1567-1576.

10. Sherman DS, Fish DN, Teitelbaum I. Assessing renal function in cirrhotic patients: Problems and pitfalls. Am J Kidney Dis 2003; 41: 269-278.

11. Laterza OF, Price CP, Scott MG. Cystatin C: An improved estimator of glomerular filtration rate? Clin Chem 2002; 48: 699-707.

12. Larsson A, Malm J, Grubb A, Hansson LO. Calculation of glomerular filtration rate expressed in $\mathrm{mL} / \mathrm{min}$ from plasma cystatin $\mathrm{C}$ values in $\mathrm{mg} / \mathrm{L}$. Scand J Clin Lab Invest 2004; 64: 25-30.

13. Imai E, Horio M, Nitta K, Yamagata K, Iseki K, Tsukamoto Y, et al. Modification of the Modification of Diet in Renal Disease (MDRD) Study equation for Japan. Am J Kidney Dis 2007; 50: 927-937.

14. National Institute of Diabetes and Digestive and Kidney Disease. Renal Data System: USRDS 2000 Annual Data Report. Bethesda, National Institutes of Health, NIDDKD, 2000.

15. Schrier RW. Role of diminished renal function in cardiovascular mortality: Marker or pathogenetic factor? J Am Coll Cardiol 2006; 47: $1-8$.

16. Cody RJ, Atlas SA, Laragh JH, Kubo SH, Covit AB, Ryman KS, et al. Atrial natriuretic factor in normal subjects and heart failure patients: Plasma levels and renal, hormonal, and hemodynamic responses to peptide infusion. J Clin Invest 1986; 78: 1362-1374.

17. Dries DL, Exner DV, Domanski MJ, Greenberg B, Stevenson LW. The prognostic implications of renal insufficiency in asymptomatic and symptomatic patients with left ventricular systolic dysfunction. J Am Coll Cardiol 2000; 35: 681-689.

18. Cerne D, Kaplan-Pavlovcic S, Kranjec I, Jurgens G. Mildly elevated serum creatinine concentration correlates with the extent of coronary atherosclerosis. Renal Fail 2000; 22: 799-808.

19. Yusuf S, Diener HC, Sacco RL, Cotton D, Ounpuu S, Lawton WA, et al. Telmisartan to prevent recurrent stroke and cardiovascular events. N Engl J Med 2008; 359: 1225-1237. 